\title{
FOTOETNOGRAFIA: VINTE E CINCO ANOS
}

\author{
Photoetnography: twenty-five has years
}

Luiz Eduardo Robinson Achutti. ${ }^{1}$

\section{http://dx.doi.org/10.52641/cadcaj.v7i1.651}

Resumo: Fotoetnografia faz 25 anos. O meu próprio trabalho constitui-se em um apanhado de mais de duas décadas de atividades acadêmicas para o desenvolvimento e conceituação do termo Fotoetnografia, quando em minha pesquisa de mestrado (UFRGS 1996) e depois retomado no doutorado (Universidade de Paris 7 Denis - Diderot 2002). No presente artigo, em forma de memorial, apresento atividades ainda anteriores aos anos noventa, que sempre apontaram no sentido de atividades multidisciplinares que culminaram nesse conceito hoje amplamente utilizado sobretudo no campo das ciências sociais.

Palavras-chave: Fotografia. Antropologia. Fotoetnografia. Antropologia visual.

\begin{abstract}
Photo-Ethnography is 25 years old. My own work constitutes more than two decades of academic activities for the development and conceptualization of the notion of PhotoEthnography, starting in my Master's research (UFRGS 1996) and later in the Doctorate (Universite Paris 7 Denis Diderot 2002). In this article, that takes the form of a memorial, I present activities even before the nineties, which always pointed towards multidisciplinary activities that culminated in this concept that is now widely used, especially in the field of social sciences.
\end{abstract}

Keywords: Photography. Anthropology. Photoethnography. Visual anthropology.

\section{INTRODUÇÃO}

Antes de expor a todos esse memorial da Fotoetnografia, que em grande parte constitui-se o memorial da minha vida, é imperativo registra a tristeza que insiste em me abater devido ao falecimento do meu amigo e incentivador Professor Mauro Guilherme Pinheiro Koury. Esse memorial há alguns meses tinha sido escrito sempre com o Mauro presente, mesmo que distante fisicamente, ele lá no Nordeste e eu aqui no Sul. Mauro Koury foi um dos grandes incentivadores da minha carreira acadêmica com vieses frequentes de interdisciplinaridade. Mauro não irá ler como

\footnotetext{
${ }_{1}^{1}$ Professor titular do Instituto de Artes da Universidade Federal do Rio Grande do Sul. Doutor pela Universidade de Paris 7 Denis - Diderot, 2002. Membro do Grupo de Pesquisa Cronobiologia Humana do Hospital de Clínicas de Porto Alegre/UFRGS Orcid: https://orcid.org/0000-0002-2721-6659

Email: robinson.achutti@gmail.com
} 
eu tanto desejava, um país desorganizado e injusto tirou Mauro do nosso convívio. Obrigado por tudo, querido, uma honra estar meu trabalho mais uma vez na tua Revista. E obrigado a equipe da revista e a todos que decidiram participar com ensaios ou artigos.

Escrever um memorial é como olhar-se no espelho do tempo, navegar com correntezas difíceis ou pilotar sob turbulências, deve-se fazê-lo sempre de modo a não perder o rumo. Não é por nada que na literatura muitos autores alertam sobre o momento inicial do texto como um enfrentamento do escritor com a página em branco, que no começo chega a ofuscar, mas aos poucos vai cedendo espaço às reflexões.

Esse breve memorial tem por objetivo dar conta do processo de vinte e cinco anos desde a criação da Fotoetnografia, e até mesmo antes. Sim minha Fotoetnografia é necessariamente resultado também de empenhos e sonhos, projetos anteriores. Assim como foram importantes amigos, professores, familiares, muitos que de uma maneira ou de outra me deram incentivo, apoio, coragem. Há pessoas que foram determinantes nesse processo ao longo do tempo, que vão dos meus pais, Aloyzio e Valderes Achutti, Ondina Fachel Leal e Jean Arlaud (ele in memória) meus orientadores no Brasil e na França. Ruben Oliven incentivador e exemplo, Etienne Samain, Cornélia Eckert, Ana Luiza Rocha, Ignês Valette, Christinne Louveau, Pascal Dibie, Remi Hess, Christine Delory-Momberger, Daniel Friedmann, Nazareth Agra Hassen, Mauro Koury, Maria da Paz Hidalgo, Fabio Lopes Alves e Comissão do Museu das Memórias In(Possíveis), Associação Psicanalítica de Porto Alegre - APPOA, entre outros.

Fotoetnografia me é muito cara, assim como meus livros todos e parte das minhas fotografias - que são meu legado a compor o que será um dia minha memória. Como disse o arquiteto genial Niemeyer, a vida é um sopro. E o que vale é a memória, afirmo eu.

\section{ANTES DE TUDO A FOTOGRAFIA. DE DAGUERRE A}

\section{FOTOETNOGRAFIA}

O mundo nunca mais foi o mesmo depois do surgimento da Fotografia, mãe das chamadas imagens técnicas, ela não apenas fez com que as obras de arte não fossem mais as mesmas, mas também não mais seriam recebidas, percebidas, apreendidas como antes. (No sentido de Benjamin, Walter)

A denominada "era da reprodutibilidade técnica" veio modificar não apenas a percepção e o fazer artístico, mas também as ciências humanas de um modo geral. Aproximando cinema e fotografia dos campos e práticas de pesquisa, primeiramente compondo meros registros da cultura 
material, registrando tipos humanos, sua arquitetura, instrumentos de trabalho, rituais, indumentária, etc. além de também registrar a própria presença do pesquisador em meio as mais diversas situações de pesquisa de campo. Ao longo do século XX, as ciências humanas aproximamse, são influenciadas por novos recursos visuais ao ponto de surgirem novas áreas que foram bem delimitando-se, chamadas Sociologia Visual e Antropologia Visual, entre outras.

\section{INTERDISCIPLINARIDADE}

Fundamental aqui defender, realçar a ideia da interdisciplinaridade. A meu ver mote e causa de tudo que fiz na minha vida. Nem sempre é fácil lidar, viver uma vida rica articulando áreas diversas, mesmo que conexas, correlatas, articuláveis, imperativo para um mundo melhor. Sempre procurei imaginar que me deparo com pessoas que valorizam essa característica fundamental do que tem sido a minha vida. Meu viver foi sempre articulando muito do que a vida oferece, buscando vieses, sempre caminhos que possam se comunicar.

Teatro, fotografia, fotojornalismo, antropologia, artes visuais, ensino, ou seja - ator, fotógrafo, antropólogo e professor são os vieses, os caminhos articulados ao longo do meu percurso de jovem até os dias de hoje. Sim, sempre subjacente subsiste meu ser político, todos somos políticos, mesmo que não queiram admitir.

Pela vida busquei relacionar, fazer comunicar esses caminhos que fui abrindo segundo minhas curiosidades, meus interesses e capacidades. Quando pequenas conquistas do passado pavimentavam os caminhos futuros.

Jovem ator e iniciante fotógrafo, tratava de me oferecer ao meu grupo também contribuindo com o fotógrafo. Por exemplo, o cartaz da primeira peça - O Matadouro, direção da carioca Ana Maria Taborda, foi fotografado por mim. Filme revelado e cópias feitas no laboratório fotográfico emprestado. Ator que trazia junto o fotógrafo à baila.

\section{NA UNIVERSIDADE E NO MUNDO}

O jornalismo muito despertou minha atenção, fotojornalismo mais especificamente. Criei uma Agência chamada Photon/Fotografia e Notícia nos anos 1980. Fotografei para Jornal do Brasil, depois Folha de São Paulo, Revista Isto É e várias empresas de São Paulo com seus jornais internos. Além da empresa RBS com seu Jornal Zero Hora, quando com o jornalista querido Carlos Urbim trabalhei para um encarte jovem chamado Zhé $\mathrm{H}$. 
No período em que trabalhei para o Jornal do Brasil, conheci o meu amigo e colega do IA da UFRGS, professor Eduardo vieira da Cunha, então repórter de texto e fotógrafo do Jornal O Globo, concorrente direto do JB. Eduardo me alertou sobre um concurso para professor de fotografia para ocupar a vaga do professor Farias. Fui atrás de livros além dos que já tinha para estudar para o concurso público federal em 1994, quando fui aprovado em primeiro lugar entre onze candidatos.

Em 1980 realizei a primeira de muitas exposições individuais e coletivas que não listarei aqui. Essa primeira exposição era chamada Achutti - Fotografias e foi realizada na Galeria Iberê Camargo do Diretório Central dos Estudantes da Universidade Federal de Santa Maria, mais de cinquenta se sucederam.

Nesse mesmo ano, fiz o registro icônico da invasão das mulheres à casa de estudante da UFRGS (CEU), considerado um marco na história de luta das mulheres gaúchas.

Em 1982 comecei a trabalhar na Coojornal, Cooperativa dos Jornalistas de Porto Alegre, minha escola em um período difícil para o jornalismo pois em plena ditadura militar. Dois anos depois, pedi demissão da Coojornal, que estava por fechar devido às perseguições e prisões de quatro dos seus dirigentes, processados pela Justiça Militar (julgamento que assisti e fotografei inteiro). $\mathrm{Na}$ época aconteceram ataques a algumas bancas de jornais e revistas no centro da cidade, o que afetava a exposição e venda do Coojornal. Passei então a trabalhar como freelancer na sucursal do Jornal do Brasil em Porto Alegre. Trabalhei nos importantes anos de 1983 e 1984, da campanha pelas Diretas Já. Foram dois anos em que estive profissionalmente inserido na luta pela volta da democracia, usando as minhas armas que sempre foram, a câmera fotográfica e minhas fotografias. Situações ímpares que geraram em mim forte emoção e boas fotos.

Algumas dessas fotos transformaram-se em ícones nacionais: A foto da queima de arquivos do DOPS, captada para o Jornal do Brasil e outras, uma das mais simbólicas e importantes: Fafá de Belém, no comício final das Diretas Já em Porto Alegre. O rito em todas as capitais do Brasil era a cantora Fafá de Belém cantar o nosso Hino nacional e, logo após, soltar uma pomba para simbolizar a paz. Desse momento fiz uma imagem ícone, se não a única e mais simbólica e importante de todo o País.

Tendo abandonado o teatro, por frustações e não me remunerar, nesse mesmo ano 1985, fui graduado Bacharel em Ciências Sociais com ênfase em Antropologia, quando, ao entrar em 1978, pensava em ser sociólogo. No decorrer do curso encontrei esse outro campo: a Antropologia, que consegui, anos depois, articular com a minha prática fotográfica, propondo para enriquecer esse campo de pesquisa o conceito da Fotoetnografia que criei, conceituei, pratiquei e defendi no 
mestrado (UFRGS.1996) e doutorado (Paris7,2002), tendo como orientadora Dra. Ondina Fachel Leal.

No mesmo ano de 1985 deixei o Jornal do Brasil e passei a ser freelancer da sucursal do Jornal Folha de São Paulo em Porto Alegre, conjuntamente com a criação de uma pequena empresa/agência fotográfica chamada Photon / Fotografia e Notícia. Pela empresa eu e meu sócio, Sylvio Sirângelo, passamos a fazer trabalhos eventuais de fotojornalismo para vários órgãos e empresas de Porto Alegre e outras capitais. Recebíamos demandas como representantes da reconhecida agência Angular (SP), muito atuante no mercado editorial e empresarial, além de outros vários clientes diretos.

Foi mais de uma década no mercado de trabalho como fotógrafo e fotojornalista, de 1982 até o ano de 1994, quando comecei meu mestrado na antropologia da UFRGS no Programa de Pós-Graduação em Antropologia Social. Foi a década de algumas viagens importantes. Eu chamava de inventário visual ou crônica visual do mundo socialista. Minha ideia era viajar, testemunhar e trazer em fotografias analógicas informações/imagens desse outro mundo pouco conhecido dos brasileiros quando sob ditadura militar.

Nesse período, 1986, na minha primeira viagem para fora do Brasil, realizei o sonho de conhecer Cuba de perto, ver com meus olhos, registrar com minhas fotos e não ter que ficar sempre sendo informado por terceiros, que em geral eram inimigos de Cuba.

Em 1988 repeti a viagem visual, daquela vez fui para Nicarágua, Manágua e várias regiões. Lá fiquei um mês e tive a oportunidade de conhecer um lugar praticamente inacessível, pela precariedade e risco de ataques na estrada. Foi inspirado em leituras de Júlio Cortázar que fui impelido a buscar Solentiname, somado à sorte de ter encontrado um australiano que levou num veleiro um grupo que eu reuni. Fui também ao norte, fronteira com Honduras, país que abrigava os Contras que invadiam a Nicarágua e matavam camponeses, ação para desestabilizar o Sandinismo implantado, via revolução, na época já em crise. Para complicar, a única forma de ir até Matagalpa e Jinotega era por meio rodoviário, correndo riscos de ataques pois rumo ao norte, perto de Honduras. Foram trinta dias muito ricos do ponto de vista de aprendizado de vida e registros fotográficos.

Essas duas incursões viabilizaram um convite do governo de Berlim Oriental, em 1989, para que eu ficasse quinze dias na cidade. Aproveitei as comemorações dos 200 anos da queda da Bastilha, em Paris, para encadear as duas viagens. Voltei, por minha conta, em 1990, para as comemorações da reunificação alemã e testemunhei o que seria simbólica e praticamente o fim do assim chamado socialismo real no mundo. Foram duas temporadas muito significativas pessoal e profissionalmente. 
Em 1993, um ano antes de tornar-me docente do Instituto de Artes da UFRGS (Universidade Federal do Rio Grande do Sul), comecei a trabalhar em um dos primeiros livros de cunho documental, que procuro fazer até os dias de hoje: o universo de trabalho do grande pintor Iberê Camargo, que veio a falecer, fato que me fez adiar o projeto por onze anos.

\section{UNIVERSIDADE, ENSINO E PESQUISA}

No ano de 1994 iniciei a minha pesquisa de mestrado e minha atividade atual de professor do Departamento de Artes Visuais do Instituto de Artes da Universidade Federal do Rio Grande do Sul.

Fiz dissertação sobre A Vila Dique, no galpão onde ocorreu a primeira experiência de separação de resíduos orgânicos de inorgânicos no Brasil, possibilitada pela chamada Coleta Seletiva implementada pela prefeitura do então Prefeito Olívio Dutra. Afastava-me aos poucos da lida do fotojornalismo, quando no ano de 1996 defendi meu mestrado em Antropologia Social, ao mesmo tempo, dava minhas aulas e fotografava, como freelancer para o Jornal do Brasil. Com o título: Fotoetnografia - Um estudo de Antropologia Visual sobre cotidiano, lixo e trabalho, meu campo de estudo foi o galpão de separação de lixo da Vila Dique. Freiras que faziam um trabalho social organizaram um grupo de doze mulheres que passaram a sustentar suas famílias por meio da venda do seu trabalho de separação do lixo seco que era reciclado. Tratava-se de um trabalho muito rico para ser abordado associando a fotografia com a antropologia.

Minha ideia foi contar/entender/difundir o cotidiano de trabalho daquelas mulheres, não apenas por meio de texto, mas também associando ao que chamei de texto visual. Essa proposta narrativa através de imagens, foi pioneira na antropologia brasileira e mundial, assim como o termo que criei e comecei a conceituar no meu mestrado - a Fotoetnografia, que é um conjunto de imagens fotográficas propostas como forma de narrar, oriundas de um trabalho de campo com o olhar e os pressupostos éticos e teóricos da antropologia. Essa "associação" objetivava conquistar o leitor e deixar mais acessível o ato de difusão dos resultados de pesquisa, pois pesquisamos para sermos lidos não apenas por nossos pares, professores, outros pesquisadores e colegas. Produzir e viver numa ilha, ou bolha, nunca me interessou, sou defensor da academia articular seu trabalho para fora dos muros das universidades.

Seria importante relatar que lá nos primeiros contatos, as catadoras não queriam ser fotografadas. Se elas soubessem que eu era fotojornalista seria pior ainda, pois a experiência delas com reportagens de jornais era péssima devido a matérias miserabilistas que haviam sido feitas. Eu me apresentei dizendo que era um trabalho para a universidade, um trabalho de tese a ser 
apresentado na universidade. Logo após minha defesa, o jornalista Carlos Urbim publicou no Caderno de Cultura do jornal Zero Hora quatro páginas sobre a minha tese, com muitas fotos, um pequeno texto de minha autoria e um brilhante texto dele. Eu soube, dias depois, que o padre tinha registrado a matéria no seu sermão. As catadoras, por terem se sentido valorizadas como trabalhadoras, colaram as páginas do jornal na parede do galpão. Foi muito gratificante pois, se não tivesse composto com a fotoetnografia, elas nunca teriam ficado sabendo da tese ou pelo menos jamais colariam páginas na parede do seu local de trabalho. Resta dizer sobre meu mestrado que foi a primeira vez no Brasil, talvez no mundo, que uma tese foi proposta com duas formas de texto, duas metades, um texto escrito/verbal e um texto visual. Em 1997 quando editado em Livro pelas editoras Palmarinca e Tomo Editorial, livro com duas capas, duas metades, entrada pelas imagens outra pelo texto, siameses inversos. Minha dissertação tinha sido aprovada com três notas 'A' por uma banca de professores reconhecidos na área: Ondina Fachel Leal (orientadora), Ruben Oliven, Cornélia Eckert (UFRGS) e Etienne Samain (Unicamp).

\section{DOUTORADO, VELHO MUNDO, NOVO SONHO}

Preparar projeto, dar aulas, viajar para entrevista da CAPES, CNPq, angústias, fotografar eventualmente para a Folha de SP. Assim foi o ano de 1998. Quando vieram os resultados, tendo concorrido à bolsa na CAPES e no CNPq, fui o único bolsista do CNPq do Brasil da área das Humanas em 1998. Vida complexa, mas sempre pode ser positiva, boa.

Lá fomos eu, minha ex-mulher e a Julia com um ano e sete meses, cheios de medos, planos, expectativas e sonhos, morar quatro anos em Paris. Na partida, quatro anos pareciam uma eternidade. Levei duas mulheres comigo a reboque do meu sonho de fazer avançar a Fotoetnografia, legitimá-la no espectro multidisciplinar da Antropologia, área maravilhosa, que, como escreveu Geertz: - antropologia propicia o diálogo entre as culturas.

Fui acolhido no Laboratoire d'Antrhopologie Visuelle et Sonore du Monde Contemporain pelo cineasta antropólogo Jean Arlaud meu orientador e amigo, infelizmente falecido há poucos anos. Arlaud teve como seu orientador de doutorado o cineasta Jean Rouch, que tive a felicidade de conhecer e fotografar. Rouch, também falecido, foi o inspirador da Nouvelle Vague, como sempre afirma o cineasta Jean Luc Godard.

Estava decidido a fazer meu campo na França e não no Brasil. Assim eu inverteria a prática dos pesquisadores franceses que sempre buscaram campo no terceiro mundo. Descobri meu campo ao visitar a $\mathrm{BnF}$ - Biblioteque Francois Mitterrand, no $13^{\circ}$ arrondissement de Paris, que estava recém entrando em operação. Fiquei fascinado pelo tamanho, beleza e funcionalidade de seu 
desenho arquitetônico. Já sabia que tinha havido protesto por parte dos trabalhadores. De fato, o início das operações foi muito difícil com seus dois mil funcionários, quase uma cidade em quatro prédios de dezoito andares em forma de livro aberto nos quatro ângulos retos de um jardim profundo maior do que um campo de futebol. Desde o primeiro dia fiquei muito curioso para poder estudar aquela "máquina” por dentro, o universo não público do trabalho, que os leitores e pesquisadores mal podiam imaginar quando do lado público esperam chegar seus livros. Só essa experiência de fazer meu doutorado naquele espaço renderia aqui um memorial de muitas páginas.

Foram muitas incursões, caminhadas, fotos, entrevistas, horas de laboratório revelando negativos preto e bancos e ampliando fotos. As imagens da minha tese optei por fazê-las em preto e branco, já que eu estava na pátria da fotografia p\&b, terra de Cartier-Bresson e Doisneau, mas também porque as diferenças entre o lado do trabalhador e o lado do público eram esteticamente enormes em termos de cores e acabamentos, que poderia parecer um exagero eu construir minha narrativa que não fosse em preto, cinzas e branco.

$\mathrm{Na}$ tese me referi a biblioteca como sendo uma cidade, a BnF guarda internamente além dos livros, dos escritórios, longos corredores e das salas de leituras, uma caserna de bombeiros, um ginásio de esportes e uma biblioteca para os funcionários. Nessa biblioteca interna à biblioteca, na sua galeria de exposições, expus em duas paredes toda a narrativa visual da minha tese. Coloquei um caderno para comentários que depois organizei em texto e foi usado à guisa de conclusão. $\mathrm{Na}$ noite de inauguração me disseram que eu estava propiciando uma aproximação entre funcionários e direção, pois fora a primeira vez que os diretores estavam colocando os pés na biblioteca dos funcionários. Isso me emocionou bastante.

Além de trabalhar na tese, criar minha filha, apreender uma cultura e a dominar o idioma, atuei como professor durante quase dois anos junto com Jean Arlaud ou como seu substituto, na parte que se referia à técnica fotográfica e, como não podia deixar de ser, minhas propostas para a fotoetnografia foram trocadas com os alunos.

Quatro anos passaram mais rápido do que eu imaginava. No começo do quarto ano, em janeiro de 2002, no dia do meu aniversário, nasceu prematuramente, de oito meses, meu Filho Eduardo Achutti.

Por fim chegara a hora de defender a tese, vender mais da metade do que tinha dentro de casa e partir de volta, não sem uma significativa tristeza. Minha banca foi formada com Jean Arlaud, Pascal Dibie (também do laboratório do Arlaud), Remi Hess escritor e sociólogo - presidente da minha banca, Mme. Christine Delory-Momberger, doutora em Ciências da Educação e Daniel Friedmann doutor pesquisador no CNRS. Recebi a nota trés honorable avec félicitations à l'unanimité $\mathrm{e}$ no seguinte momento Mme. Delory convidou-me para publicar minha tese em Paris, o que ocorreu 
no ano de 2004, L’Homme dans la Photo pela Editora Teraédre, Paris. Por uma dessas coincidências da vida, no mesmo ano em que ela foi publicada aqui no Brasil $A$ Biblioteca Jardim, Editora da UFRGS $\boldsymbol{e}$ Tomo Editorial, Porto Alegre.

Em 2007, convidado, publiquei artigo na edição 37 de janeiro da revista l'Ethnologie Française, Ârret Sur l'image - Photographie et anthropologie, uma das principais revistas de antropologia do mundo. Nesse mesmo ano comecei a dar aulas para os alunos de mestrado e doutorado do Curso de Pós-Graduação em Antropologia Social da UFRGS. Foi uma satisfação poder colaborar no programa em que realizei meu mestrado e no departamento onde fiz minha graduação. Desde o início solicitei que minhas aulas fossem oferecidas para todos os alunos de mestrado e doutorado de toda a UFRGS. Uma experiência ótima que valeria um artigo. Minha colaboração durou até o ano de 2014. Divergências também decorrentes do fato de minha área de origem e atuação ser as imagens e não apenas a palavra escrita acabaram por me afastar do programa.

\section{PSIQUIATRIA E PSICANÁLISE}

Como professor do curso de pós-graduação em antropologia social do curso de Antropologia da UFRGS, fui convidado em 2012 para interagir e levar a Fotoetnografia para um laboratório de pesquisa no curso de Medicina da UFRGS, no Hospital de Clínicas de Porto Alegre, Laboratório de Cronobiologia e Sono liderado pela Professora Dra. Maria Paz Hidalgo. Cooperei com a equipe de pesquisa em campo em duas regiões quilombolas aqui do RS: Cantão das Lombas e Botinhas, que ficam no caminho entre Porto Alegre e a Praia de Cidreira. Em função desses trabalhos, expus na semana científica do Hospital de Clínicas de Porto Alegre.

Provavelmente, em anos, pela primeira vez, as artes visuais e antropologia, /Fotografia/fotoetnografia participaram de uma semana científica no Hospital De Clínicas de Porto Alegre, ressaltando assim, a minha característica interdisciplinar. A prática e a utilização da fotografia em Antropologia devem ser analisadas e compreendidas de maneira menos simplista. Além de o mundo estar se tornando cada vez mais visual, parece importante reafirmar que a Antropologia não é uma ciência estática, mas, ao contrário, uma ciência em constante mutação, e isso não poderia aliás ser diferente, já que se trata de uma disciplina que estuda, entre outros, as dinâmicas sociais de populações que residem nos grandes centros urbanos sem, é claro, abandonar o estudo das sociedades mais tradicionais que vivem nas fronteiras do mundo moderno e permanecem muito distantes, culturalmente falando, desses grandes centros. Essa mutação exige um questionamento constante do savoir-faire antropológico, que já utiliza a fotografia e, ao que 
parece, continuará utilizando cada vez mais, não somente pela riqueza que acrescenta ao conhecimento, como também por suscitar grande interesse no público.

\begin{abstract}
Atualmente, os antropólogos - com preocupações de ordem epistemológica - não dão atenção somente à teoria e aos problemas de ética e da prática de pesquisa que ocorrem em campo, mas também se interessam pela questão da restituição e dos diferentes estilos e possibilidades de escritura. De fato, está se tornado essencial para os antropólogos refletir sobre as diferentes formas de escritura e restituição, pois seus interlocutores não são mais, como antigamente, exclusivamente seus pares acadêmicos, mas também os membros das comunidades estudadas e o público em. Dessa forma, com a consciência da necessidade de dar retorno de suas pesquisas, os antropólogos não podem mais dar conta de seus trabalhos como faziam há oitenta anos. (ACHUTTI, 2004, p.74)
\end{abstract}

Nos primórdios, o fazer em imagens, quaisquer fossem elas, era muito difícil, fatores limitadores eram a sensibilidades baixas dos filmes, lentes pouco luminosas, câmeras mais pesadas e completamente manuais. Fosse nos tempos de hoje, mesmo Malinowski sendo um fotógrafo limitado não teria raiva da fotografia e nem errado o foco de mais da metade de suas mil e cem fotografias de campo, arquivadas na London School os Economics. Talvez hoje usasse um moderno smartphone e não teria apelidos jocosos. Como fotógrafo que demorava para encontrar o foco, recebeu atuando nas Ilhas Trobriand o apelido de TOPWEGIGILA (Young, 1998, p.5), no idioma local, o homem das calças frouxas, aparentemente devido ao seu cacoete de sungar as calças durante o tempo em que procurava o foco. De fundamental importância, o aumento a interdisciplinaridade deve-se muito as alterações de ordem tecnológica e aos estudos sobre os meios visuais, como sabemos hoje.

\title{
8. PRÉ-PANDEMIA
}

A Fotoetnografia que criei há vinte e cinco anos pode até tornar-se um álbum de família, conforme o que me correu há dois anos passados. Quando do meu trabalho de campo, defesa e depois publicação em livro eu fotografei muitas pessoas várias parentes entre si, vindas do meio rural morar na periferia de Porto Alegre. Há dois anos uma menina de uma das minhas fotos que não tinha um ano de idade, que eu nem lembrava de ter fotografado nos braços da então jovem mãe, a Diêniffer encontrou-me via Internet, veio dizer que eu detinha uma parte da história de vida dela e de seus parentes, pediu meu livro e algumas fotos. Foi inusitado, emocionante a tal ponto que me propiciou mais uma interação interdisciplinar com um grupo de estudos da Associação 
Psicanalítica de Porto Alegre - APPOA. Em cooperação com eles, retomamos aquele trabalho de pesquisa de vinte e cinco anos passados, fomos conhecer a menina de colo, hoje uma adulta que trabalha na área de pedagogia. Voltamos a casa do seu avô fizemos mais fotos, vídeos, conversamos sobre o passado e o presente deles, seus parentes e da Vila Dique. Trabalho que foi apresentado no congresso dos 30 anos da APPOA no final de 2019. Hoje esse trabalho de retomada/reestudo da Vila Dique faz parte do primeiro museu virtual com plano museográfico do Brasil, lançado no dia 22/05/2021- Museu das Memórias (In)Possíveis.

Já mais de um ano de incertezas e erros, no caso do Brasil. As casas das pessoas ancoram tudo que antes era vontade e apostas de se viver em grupo. A vida só se faz possível em sociedade, diferentes grupos que comungam e fazem prosperar características culturais próprias, teias de significados que nos sustentam enquanto grupo. (no sentido de Geertz). Perigos, doenças, sejam elas virais ou fantasmas fascistas do passado, desunem, reduzem as pessoas a solidão. A segurança por auto reclusão, proteção pode ser apenas aparente ou salvação, saberemos.

Grupos, sociedade, solidariedade, cooperação, antropologia, fotografia e Fotoetnografia são a vida. Que tudo seja possível para a gente continuar, como aqui agora, lá no futuro 50 anos da Fotoetnografia.

A labuta e a luta valem a vida. 


\section{REFERÊNCIAS BIBLIOGRÁFICAS}

ACHUTTI, L.E.R. Fotoetnografia, um estudo de antropologia visual sobre cotidiano, lixo e trabalho. Porto Alegre: Tomo Editorial/Livraria Palmarinca, 1997.

ACHUTTI, L.E.R. Fotoetnografia da Boblioteca Jardim. Porto Alegre: Tomo Editorial/Editora da UFRGS, 2004.

ACHUTTI, L.E.R. L'Homme sur la photo, manuel de photoethnographie, Paris: Tèraèdre, 2004.

GEERTZ, C. A Interpretação das Culturas. Rio de Janeiro: Guanabara Koogan S.A., 1989.

YOUNG, M. Malinowski’s Kiriwina: Fieldwork, Photographie 1915-1918. Chicago: The University of Chicago Press, 1998.

\section{Internet -}

ACHUTTI, LER. Livro do meus 45 anos de fotografia.

https://issuu.com/robinson.achutti/docs/livro achutti fotos que vivi web issuu separado 02 maio, 2021.

ASSOCIAÇÃO PSICANALÍTICA DE PORTO ALEGRE, APPOA. Museu das memórias (In)Possíveis. https://museu.appoa.org.br/site/, julho 2021. 
ASSOCIAÇÃO PSICANALÍTICA DE PORTO ALEGRE, APPOA. Entrevista para o Museu das memórias (In)Possíveis falando sobre a revisita ao meu mestrado na Vila Dique.

https://www.youtube.com/watch?v=WdDkGX4oLLs, abril 2021

ASSOCIAÇÃO PSICANALÍTICA DE PORTO ALEGRE, APPOA. Vídeo volta a Vila Dique vinte anos depois. https://youtu.be/4w rsa4Y 5Y, outubro 2019.

\section{CALEIDOSCÓPIO DO TEMPO -}
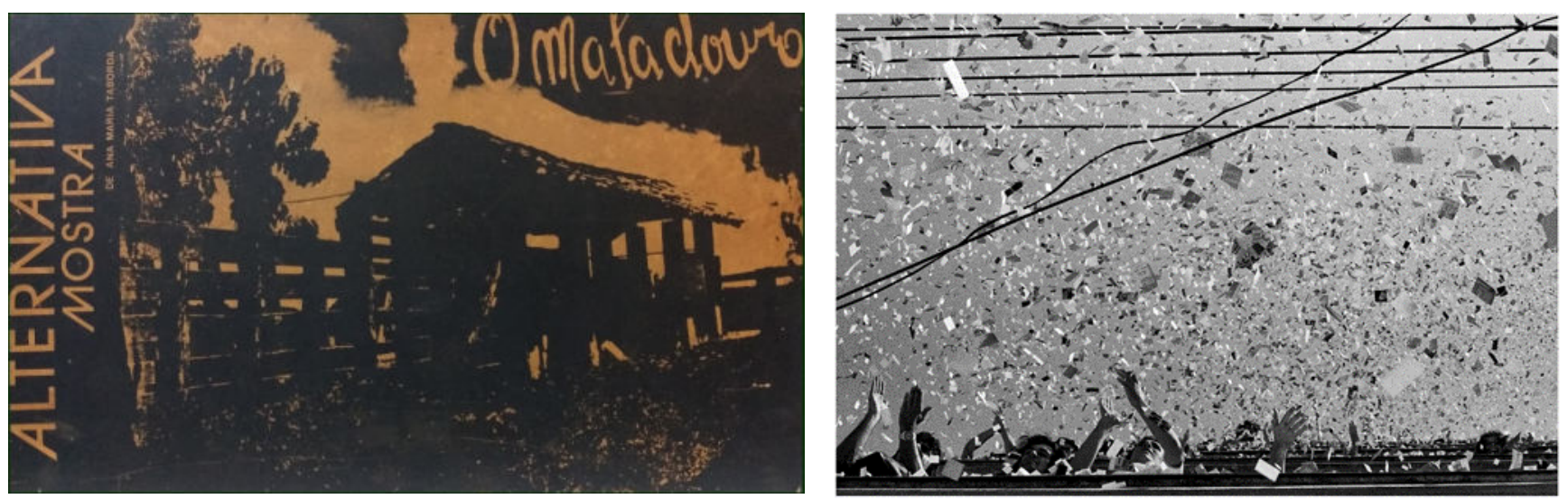

Invasão da CEU 


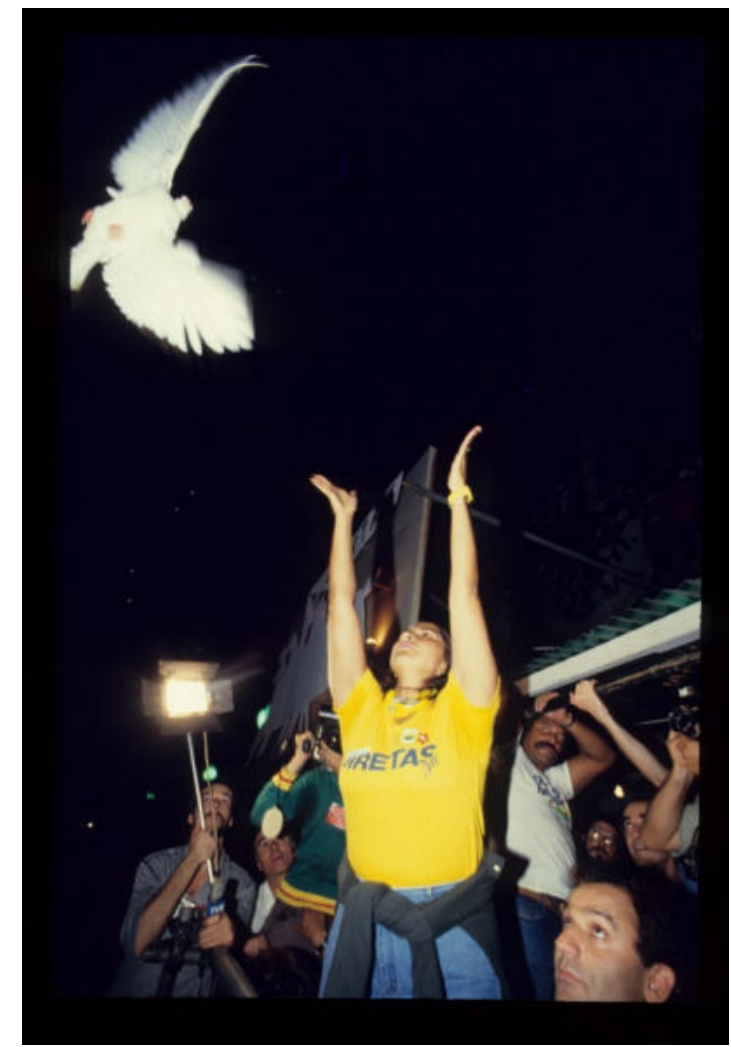

Diretas Já

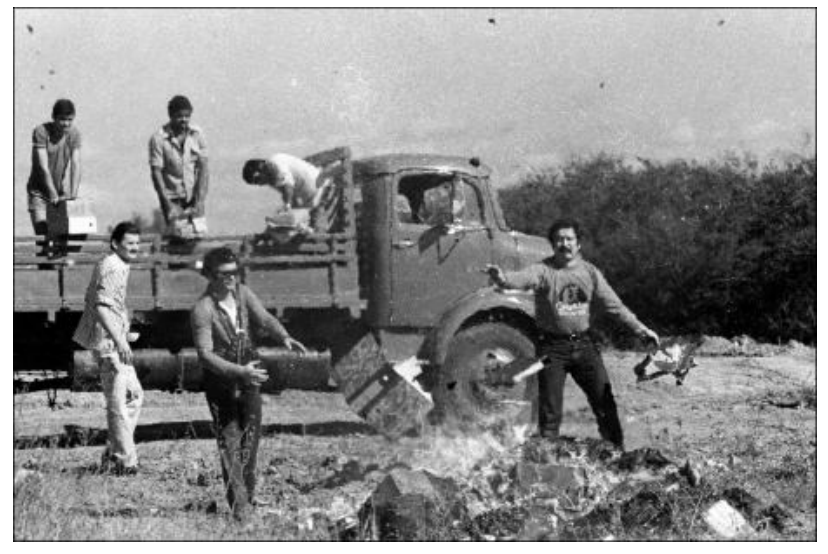

Queima arquivos DOPS

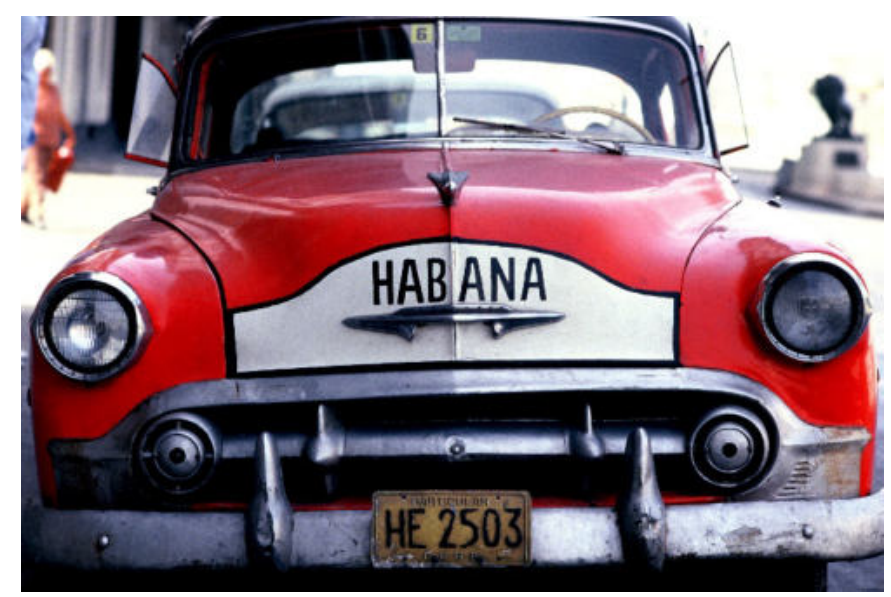




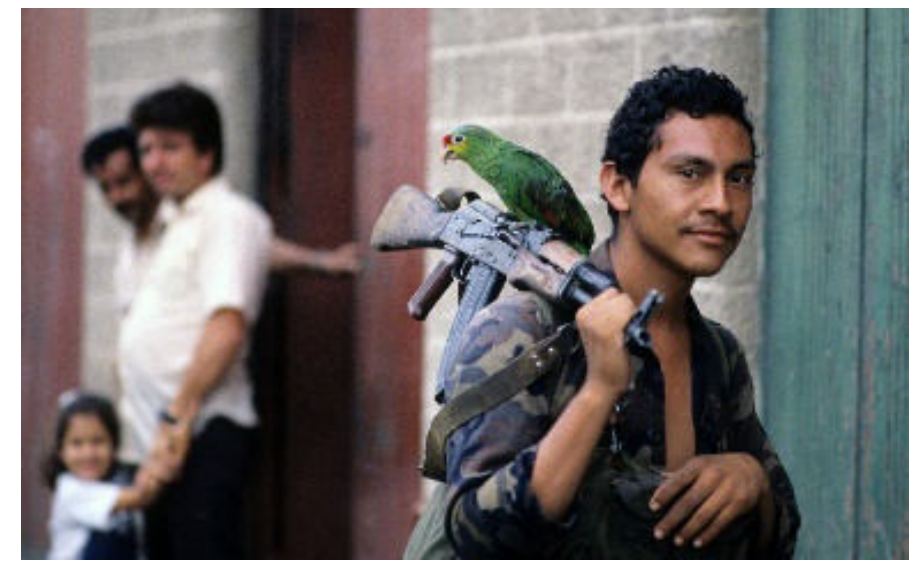

Jinotega/Nicarágua
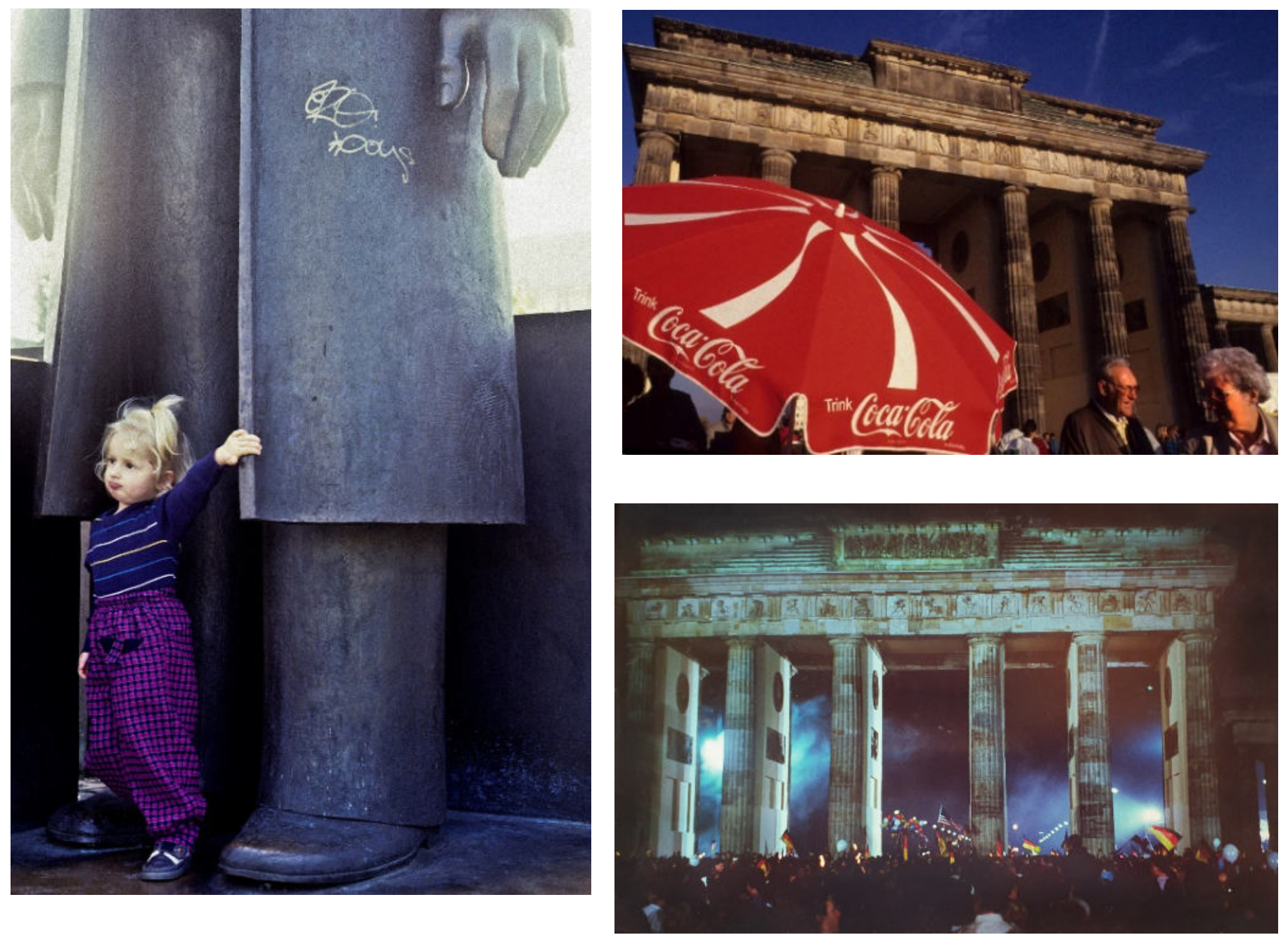

Berlin 

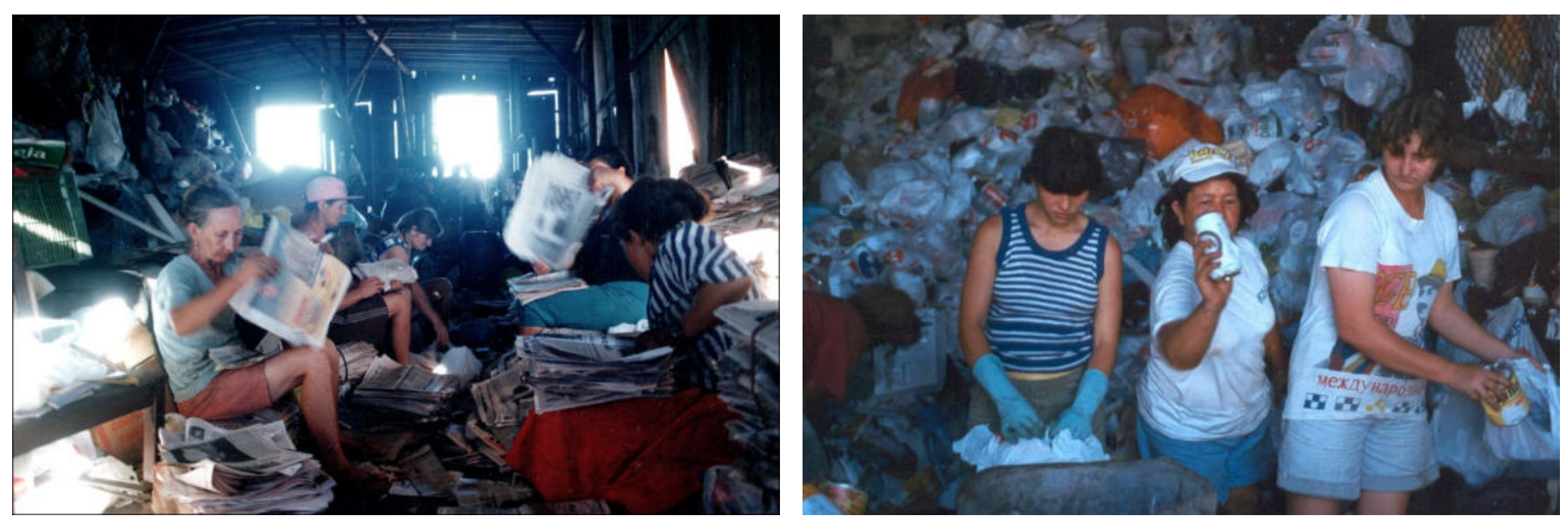

Vila Dique
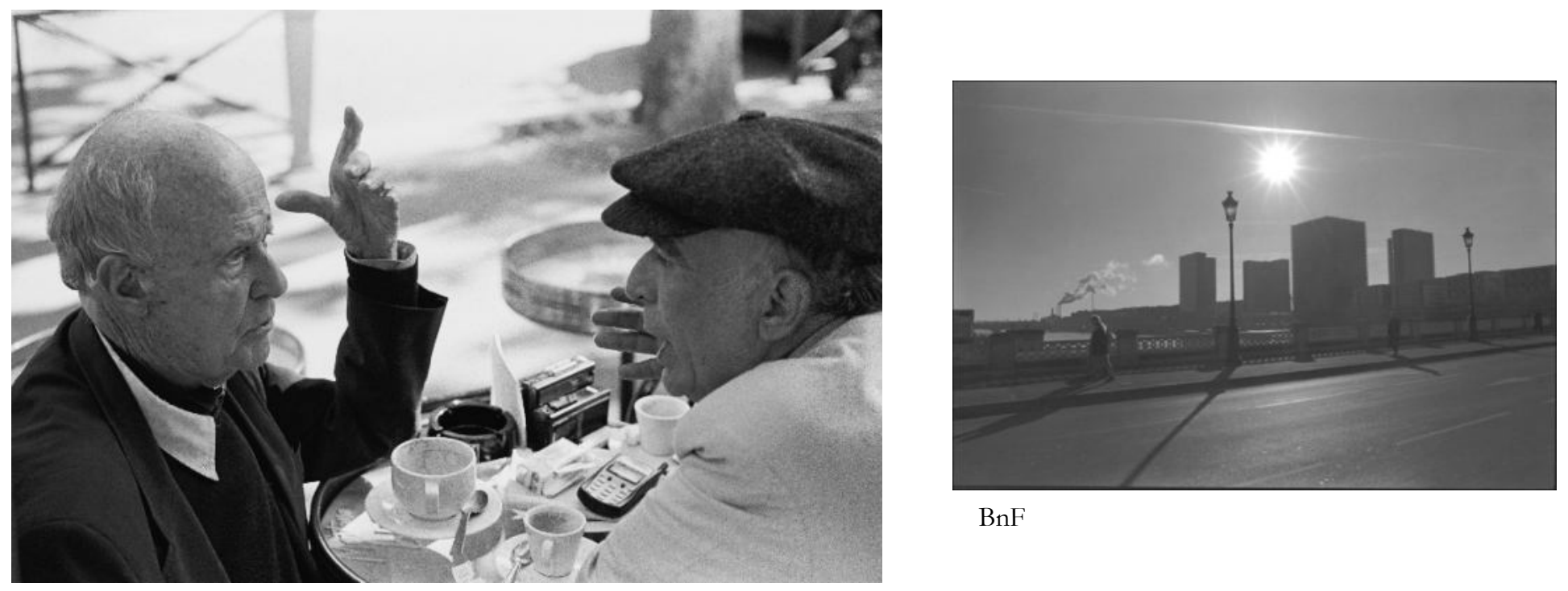

$\mathrm{BnF}$

Jean Rouch - Jean Arlaud 

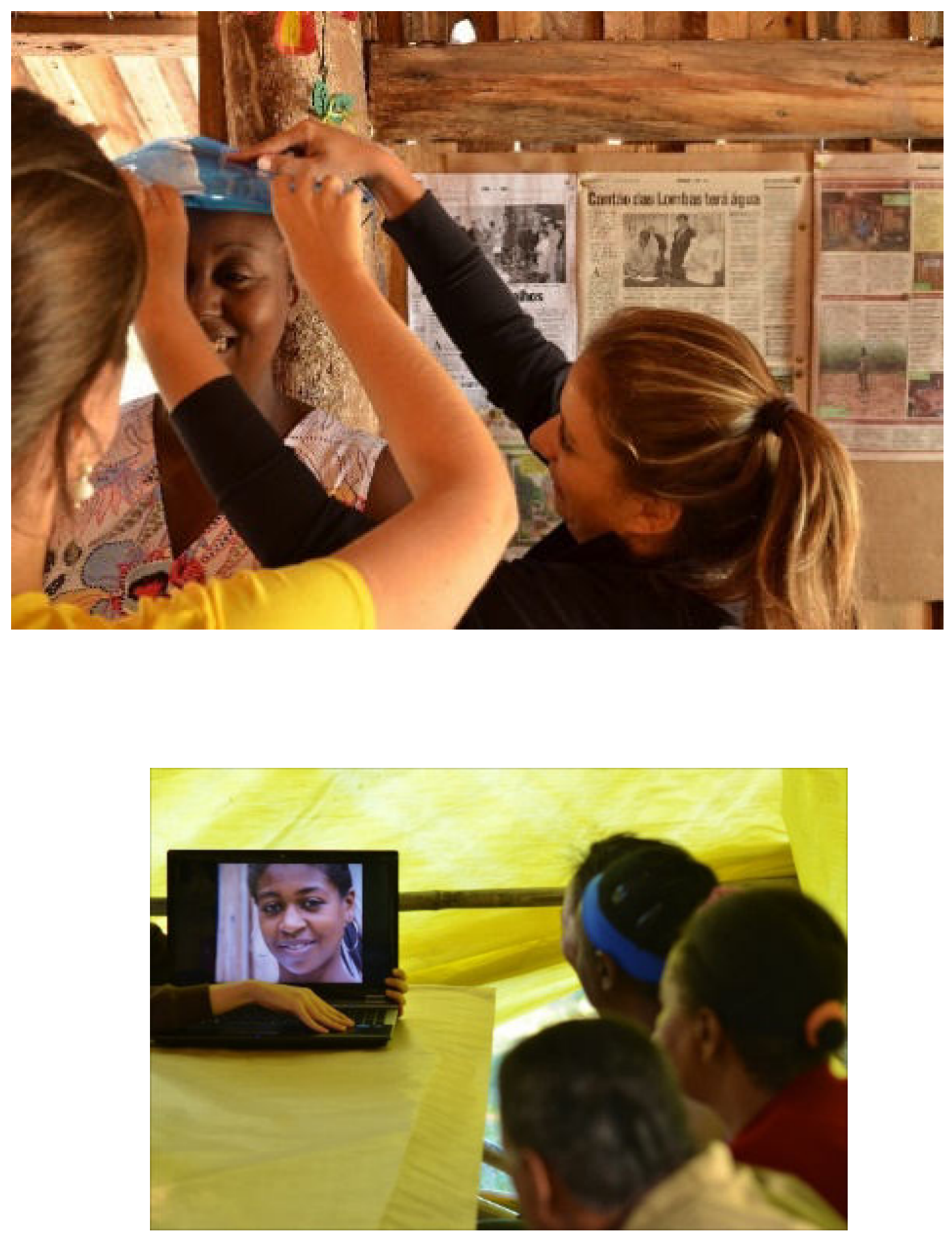
Região Quilombola

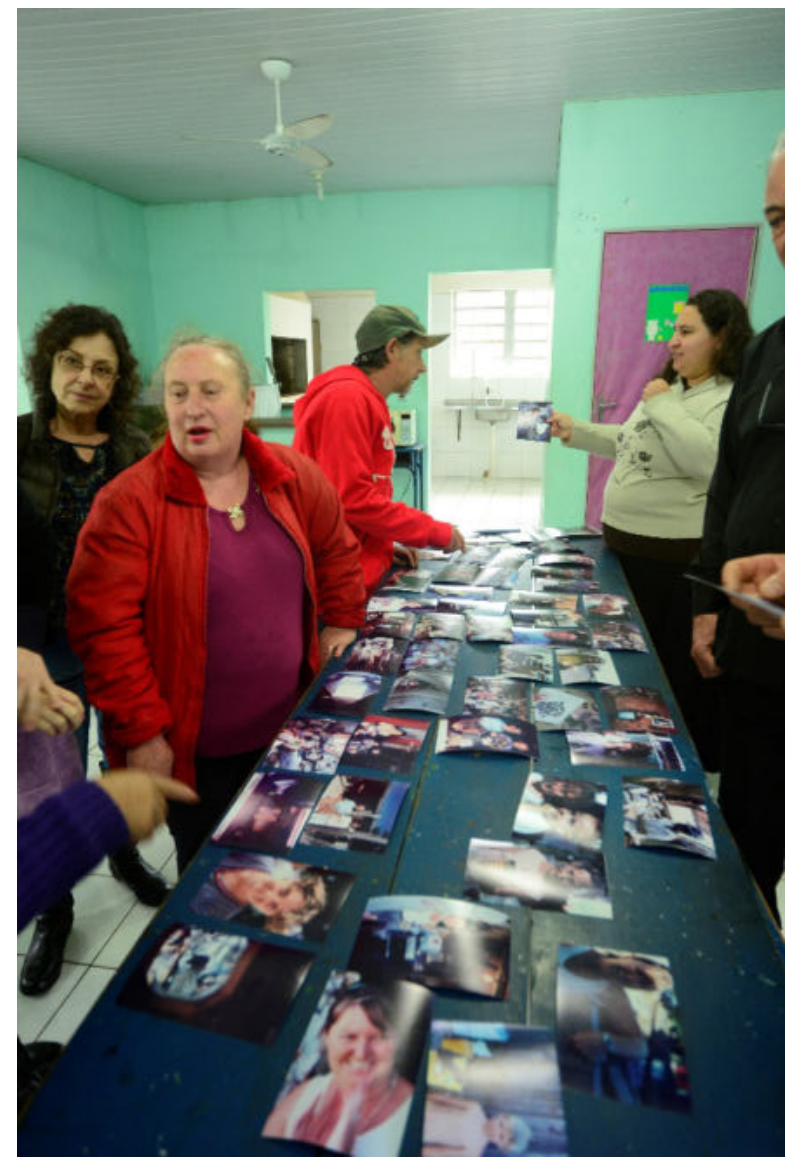

De volta a Vila Dique com APPOA

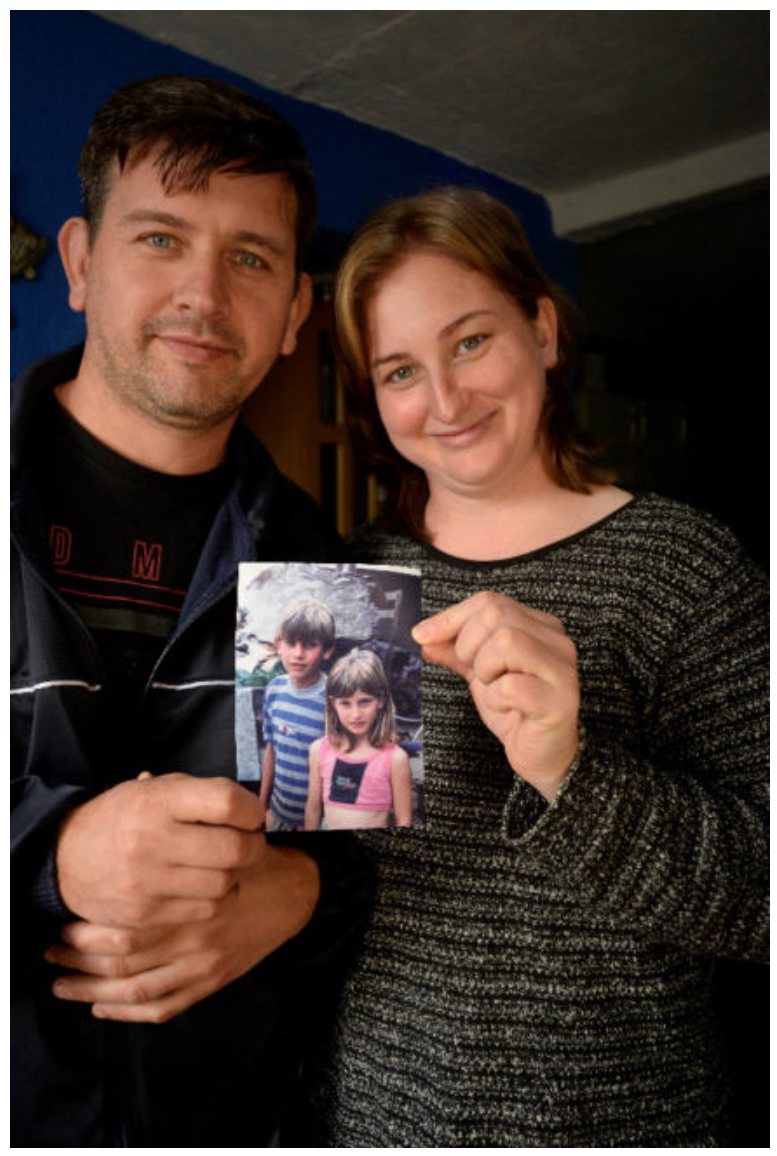




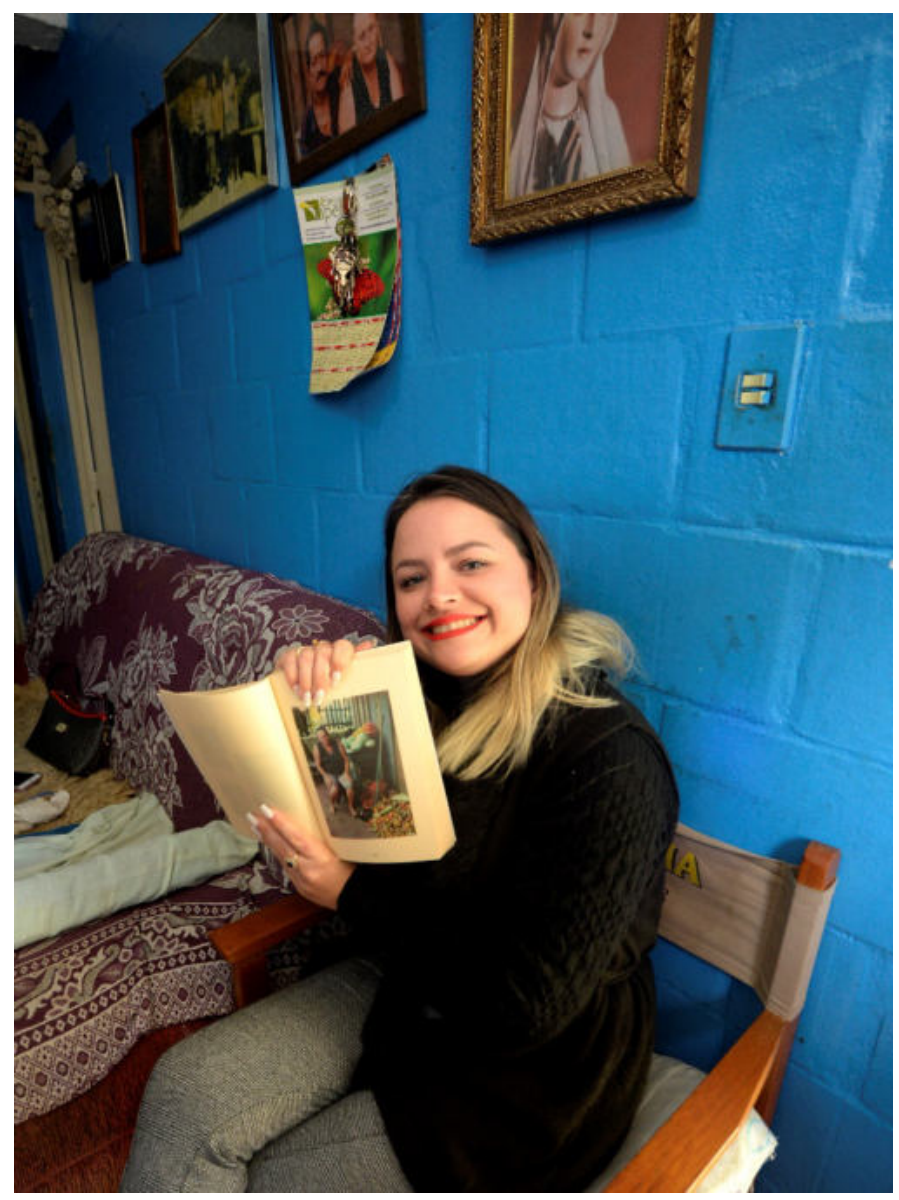

Diêniffer 
Livros Fotografia e Fotoetnografia

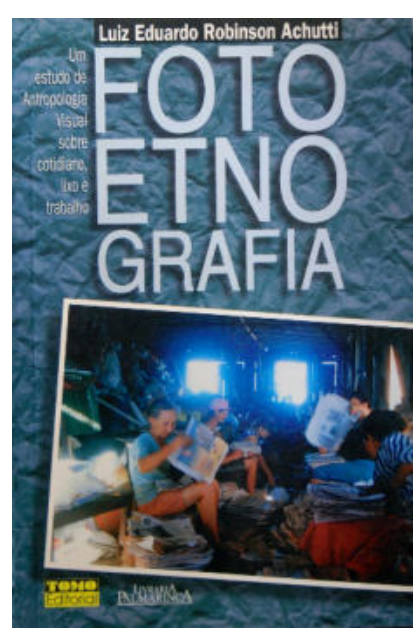

Dissertação de Mestrado

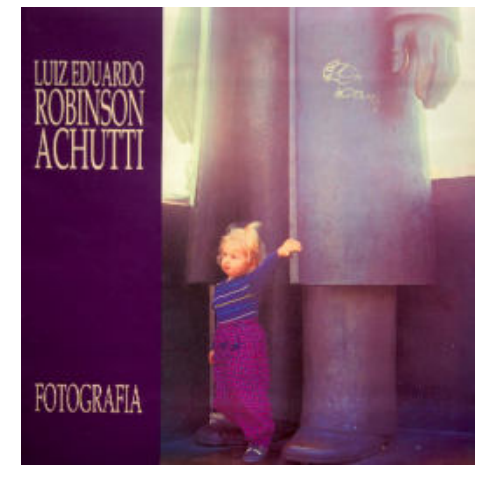

20 anos de Fotografia

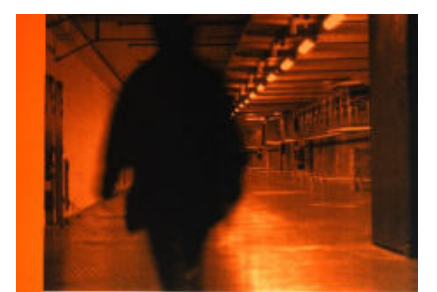

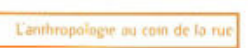

Luiz Eduardo Robinson Achutti

L'Homme sur la photo
manuel do photoet hnoorapituo

masum the

回Téraèdre

. 뻬|ㅔㅣㅔ

Tese Doutorado

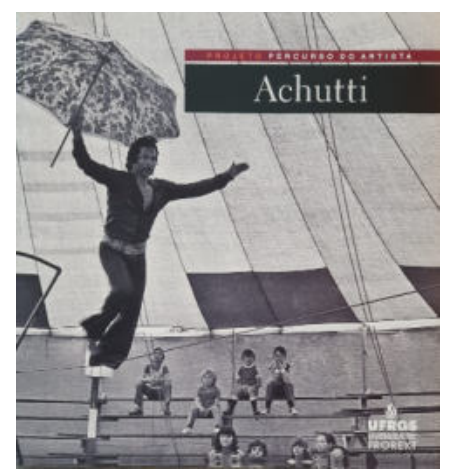

35 anos de Fotografia

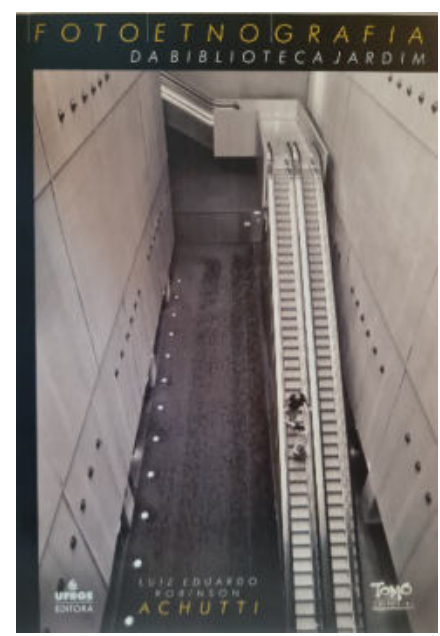

Tese Doutorado

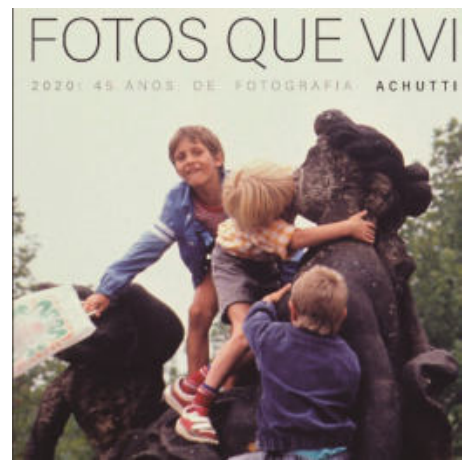

45 anos de Fotografia 